YAK 351

ББК 67.401.11

DOI 10.22394/1682-2358-2017-5-68-75

O.V. Bryantseva, Candidate of Science (Physics and Mathematics), Docent, Professor of the Informatics Department, Saratov State Academy of Law

I.I. Bryantsev, Candidate of Sciences (Sociolozy), Docent of the Public Administration Department, Povolzhsky Institute of Management named after P.A. Stolypin, Branch of the Russian Presidential Academy of National Economy and Public Administration

\section{THE DEVELOPMENT OF LEGISLATION \\ ON THE PROTECTION OF INFORMATION \\ AS AN ELEMENT \\ OF NATIONAL SECURITY SYSTEM}

The changes in legislation for the protection of information caused by the development of information technology and changes in the world and society are considered. Changes in legislation are analyzed from the point of view of strengthening national security. The discreet role of the state in the security system of cultural-historical and democratic values of the society is postulated.

Key words and word-combinations: national security, information security, telecommunication network.
О.В. БрянцеВа, кандидат физико-математических наук, дочент, профессор кафедри информатики Саратовской государственной юридической академии (email: obryanceva@yandex.ru)

И.И. Брянцев, кандидат соииологиеских наук, дочент кафедри государственного и муниципального управления Поволжского института управления имени П.А. Стольпина - филиала Российской академии народного хозяйства и государственной службы при Президенте РФ (email: iibry@yandex.ru)

\section{РАЗВИТИЕ ЗАКОНОААТЕ $\Lambda$ СТВА О ЗАЩИТЕ ИНФОРМАЦИИ КАК ЭАЕМЕНТ СИСТЕМЫ НАЦИОНААЬНОЙ БЕЗОПАСНОСТИ}

Аннотация. Рассматриваются изменения в законодательстве по защите информации, вызванные развитием информационных технологий и трансформациями в мире и обществе. Изменения в законодательстве проанализированы с точки зрения усиления национальной безопасности. Постулируется особая роль государства в системе защиты культурно-исторических и демократических ценностей общества.

Ключевые слова и словосочетания: национальная безопасность, информационная безопасность, информационно-телекоммуникационные сети.

$\mathrm{H}$ ационамьная безопасность госуАарства - важный аспект его функционирования. Кроме обороны страны, Аля обеспечения национальной безопасности необходимы государственная, общественная, информационная, экологическая, 
экономическая, транспортная, энергетическая безопасность, безопасность мичности [1]. События последних мет, проявившиеся в глобальном геополитическом пространстве и непосредственно связанные с формированием информаџионной составцяющей, весьма наглядно свидетельствуют о возрастании роли информаџионной компоненты в системе наџиональной безопасности. К наиболее ярким примерам можно отнести политические спекумяџии вокруг обвинения России в ее якобы вмешательстве в выборы президента США и хакерские атаки, приписываемые северокорейскому киберсообществу. Национальная безопасность как система формируется на базе сложных многоуровневых структур взаимосвязанных между собой эмементов. ОАним из существенных компонентов этой системы следует рассматривать информационные технологии, развитие которых, как справеАливо отмечают исследователи, является неотъемлемой частью построения информационного общества, на основе доступности размичных информационных ресурсов, что и актуализирует значимость информационной безопасности [2; 3] .

Информационные технологии формируют технологическую базу Аля реализации управленческих решений в разных сферах деятельности как внутри государства, так и на межАународном уровне с учетом принятой и реализуемой государственной политики. Российская Федерация явмяется одним из основных геополитических субъектов современного глобального информационного общества и приверженцем международных принципов и подходов его формирования, определенных Окинавской хартией глобального информаџионного общества (2000), Аекмараџией принџипов «Построение информаџионного общества - глобальная задача в новом тысячелетии» (2003) ПАаном действий Тунисского обязательства (2005), что обозначено в Указе Президента РФ от 9 мая 2017 г. № 203 «О Стратегии развития информационного общества в Российской Федераџии на 20172030 годы» [4] .

В связи с этим особую актуальность приобретают вопросы, связанные с законодательным регулированием данной сферы с целью обеспечения защиты интересов общества и государства. Авижущей силой, которая может обеспечить динамическое развитие соџиума и конкурентоспособность госуАарства, выступает его способность производить, потребцять, распределять и обменивать информацию и таким образом формировать базу Аля современной постиндустриальной экономики. Создание необходимых условий Аля этого - насущная задача органов вмасти размичных уровней, которые реализуют их через опредемение как внешних геополитических, так и внутренних приоритетов Аля обеспечения суверенитета и национальной безопасности.

Сфера развития законодательства в области обеспечения информационной безопасности, выявление складывающихся тенденџий и основных проблем стало предметом исследования многих российских ученых [5-7]. В частности, процесс формирования правовой системы обеспечения международной информационной безопасности, а также системы информационной безопас- 
ности в рамках законодательства Российской Федерации рассматривается в работах Т.А. Поляковой и Аругих авторов [8] .

В контексте проводимых в этой сфере исследований целесообразным преАставляется подхоА, позволяющий изучать компонент информаџионной безопасности в общей структуре наџиональной безопасности через анализ вносимых в соответствуюшие законодательные акты изменений, что позволяет выявлять формирующиеся приоритеты и направления в реализуемой политике.

Первый закон по защите информации быц принят в 1995 г. [9] , Аоктрина информационной безопасности - в 2000 г. [10], а в 2006 г. вступил в сику Федеральный закон от 27 июля 2006 г. № 149-Ф3 «Об информаџии, информационных технологиях и о защите информации» [11], который действует и сегодня.

За прошедшие годы произошии большие изменения в информационной сфере, в применении информационных технологий, в развитии эмектронного правительства [12], что усилило значимость информационной безопасности. Все изменения отражацись в нормативно-правовых актах по защите информации, в частности, в Законе № 149-ФЗ. На начало 2017 г. принято двадџать его реАакций. С начала 2017 г. принято еще шесть реАакций, действующая (на 1 октября) - 24-я, а остальные вступают в силу с 1 ноября 2017 г. и 1 января 2018 г. соответственно. В декабре 2016 г. Указом Президента РФ была утверждена новая Аоктрина информаџионной безопасности [13], одной из правовых основ которой явмяется Закон № 149-ФЗ.

Рассмотрим изменения в данном Законе, произошедшие более чем за десять мет с точки зрения национальной (информационной) безопасности. Этот Закон по-прежнему регламентирует отношения, возникающие при использовании информационных технологий, при осушествлении поиска, хранения, производства, передачи и защиты информащии.

Первые изменения были внесены в 2010 г., - через четыре года после его принятия. Введено понятие эмектронного документа, в связи с чем изменена ст. 11 «Аокументирование информации». Усимена роль электронного документа, подписанного электронной цифровой подписью. Ее законодательное закрепление как основного и практически единственного IT-решения по обеспечению подлинности позволяет сделать электронные документы равнозначными документам на бумажном носителе, если иное не предусмотрено федеральным законодательством.

Государственным органам и органам местного самоуправления теперь вменяется в обязанность обеспечение доступа к информации о своей деятельности и с использованием информационно-телекоммуникационных сетей, в частности Интернета (ст. 8). Изменена ст. 14 «Государственные информационные системы». Содержащаяся в сетях информаџия признается офиџиальной, а соответствующие государственные органы доцжны обеспечить ее достоверность и актуальность, а также доступ к ней и ее защиту. Указанные поправки направлены на дальнейшее развитие Аоктрины информаџионной безопасности Российской Федераџии, закрепляющей при- 
оритеты по правовому обеспечению информаџионной безопасности Российской Федераџии на принџипах законности, баланса интересов граждан, общества и государства в информаџионной сфере и обеспечении гарантий конституционных прав и свобод человека и гражданина на доступ к информаџии и предоставление полноџенных возможностей для деятельности в информационной сфере.

Аальнейшие изменения были внесены Федеральным законом от 21 июля 2011 г. № 252-Ф3. В ст. 12 о государственном регулировании применения информационных технологий бым добавлен п. 4 об обеспечении информационной безопасности детей, что, несомненно, явцяется актуальным компонентом в системе наџиональной безопасности, отвечающим за информационнопсихологическую безопасность и создающим правовую основу дяя развития и реализации мер, направленных на поддержание и укрепление здоровья нации и защиту индивидуальной психики и общественного сознания.

Сиедующим шагом по усимению информаџионной безопасности стало введение Федеральным законом от 28 июля 2012 г. № 139-ФЗ ст. 15.1. «Единый реестр доменных имен, указателей страниџ сайтов в сети "Интернет" и сетевых аАресов, позволяющих идентифицировать сайты, содержащие информацию, распространение которой в Российской Федерации запрещено». В ней говорится о создании автоматизированной информаџионной системы с включением в нее доменных имен и сетевых аАресов соответствующих сайтов, определены органы, осуществляющие создание, формирование и ведение такого реестра - это федеральные органы исполнительной власти, контролирующие средства массовой информации, массовых коммуникаций, информационных технологий и связи. Прописаны основания аля включения в реестр. Это порнографические материалы, связанные с несовершеннолетними, информация, касающаяся наркотических и психотропных средств (способы и методы изготовления, использования и распространения), а также призывы к самоубийству и способы его совершения.

С изменением в обществе и развитием информационных технологий эта статья менялась, в частности, добавмялись следующие основания Аля включения в реестр: информация о пострадавшем от противоправных действий несовершеннолетнем, распространение которой запрешено федеральным законодательством; информация, нарушаюшая требования федерального законодательства по государственному регулированию организаџии и проведения азартных игр, о запрете проведения азартных игр с использованием Интернета; информация о способах, методах разработки, изготовления и использования размичных наркотических средств; информация о розничной продаже Аистанционным способом алкогольной, различной спиртосодержащей проАукщии, розничная продажа которой ограничена или запрещена законодательством.

Федеральным законом от 7 июня 2013 г. № 112-Ф3 введено понятие информации в форме открытых данных - это общедоступная в Интернете информация, допускающая автоматизированную обработку дмя ее повторного использования, регламентировано ее размешение. В связи с этим изменены ст. 13 
«Информационные системы» и ст. 14 «Государственные информационные системы». Оператор информационных систем должен обеспечить возможность размещения информаџии в форме открытых данных. Аоступ к информации из государственных информационных систем дается только тем, кто прошел авторизаџию в единой системе идентификации и аутентификации, тем самым повышается ответственность пользователей.

В Федеральный закон от 2 июля 2013 г. № 187-ФЗ добавлена ст. 15.2, регламентирующая порядок ограничений на доступ к информаџии, распространяемой с нарушениями исключительных прав на фильмы. Соответственно, это введено в сферу деятельности Законом № 149-ФЗ (ч. 2, ст. 1). Правообладатель при обнаружении в сети фильмов, распространяемых без его разрешения или при нарушении законодательства, вправе обратиться в соответствующие органы с заявлением о принятии мер по ограничению доступа к Аанным информационным ресурсам. В статье прописаны сроки и порядок мер по ограничению доступа к данной информации и об отмене ограничений. В связи с принятием новой ст. 17 об ответственности за нарушение в сфере информаџионных технологий и защиты информаџии введена ч. 4 о том, что владельцы сайта и провайдеры хостинга не несут ответственности переА правообладателями и пользователями за ограничения доступа к информации.

В 2014 г. законодатель изменил ст. 15.2, расширив ее применение на авторские и (или) смежные права, заменив нарушения исключительных прав на фильмы на нарушение авторских и (ики) смежных прав.

В декабре 2013 г. были внесены изменения в статью о государственных информационных системах (ст. 14). Согласно этим изменениям государственные информационные системы создаются и эксплуатируются в соответствии с законодательством о контрактной системе в сфере закупок. Введена ст. 15.3 «Порядок ограничений доступа к информации, распространяемой с нарушением закона» напрямую связанная с обеспечением наџиональной безопасности. Имеется ввиду информация, размещаемая в информационно-коммуникационных сетях, о призывах к массовым беспорядкам, әкстремистской деятельности, участию в массовых мероприятиях, проводимых с нарушением закона.

С развитием информационно-коммуникационных технологий и Интернета появилась необходимость регламентирования информации, размещенной в сети и в информаџионных системах. В связи с этим в Закон № 149-ФЗ были внесены изменения Федеральным законом от 5 мая 2014 г. № 97-Ф3, в частности, добавлена ст. 10.1 «Об обязанностях организатора распространения информаџии в сети Интернет». Аано определение организатора информаџии как миџа, обеспечивающего работу информаџионных систем и программ, преАназначенных для приема, переАачи, обработки эмектронных сообщений пользователей в Интернете. О начале своей деятельности он домжен уведомить соответствующий орган. Информацию о фактах таких действий и информацию о пользователях он обязан хранить в течение шести месяџев с момента окончания их и предоставмять

72 Bulletin of the Volga Region Institute of Administration • 2017. Vol. 17. № 5 
соответствующим органам в целях безопасности Российской Федерации или для оперативно-розыскной деятельности, исполнять требования к оборудованию и программам. Прописано, на кого положения данной статьи не распространяются.

В июле 2016 г. Федеральным законом от 6 июля 2016 г. в Закон № 374-Ф3 были внесены изменения в ст. 10.1 об обязанностях организатора распространения информации. В ч. 3 ст. 10.1 введен п. 2, вступающий в силу с 1 июля 2018 г., обязывающий хранить эмектронные сообщения пользоватемей Интернета до шести месяџев после окончания их приема, передачи, доставки, обработки. При Аополнительном кодировании сообщений организатор распространения информации обязан представцять в федеральный орган исполнительной власти в области обеспечения безопасности информаџию, необходимую дмя декодирования принимаемых, передаваемых, доставляемых и (ими) обрабатываемых эмектронных сообщений.

В связи с введением ст. 10.1 в июле 2014 г. появилась ст. 15.4, регламентирующая порядок ограничения доступа к информаџионному ресурсу организатора распространения информации в Интернете.

Федеральный закон от 24 ноября 2014 г. № 364-Ф3 изменил ст. 10, обязав владельцев сайтов размещать на них информацию о своем местонахождении, аАресе, наименованиях, аАресе электронной почты дмя направления ему заявцения о нарушении авторских и (ики) смежных прав. Этот же закон ввел ст. 15.6 о порядке ограничения доступа к сайтам, где неоднократно размещалась информаџия, нарушающая авторские и (или) смежные права, ст. 15.7 о внесудебных мерах по прекрашению нарушения авторских прав в информационно-коммуникационных сетях, в которой прописаны меры и сроки, в которых их можно предпринимать.

В декабре 2014 г. внесены изменения в статьи, касающиеся информационных систем. В частности, информационные системы, используемые государственными органами, органами местного самоуправления, государственными и муниџипальными унитарными предприятиями, государственными и муниципальными учреждениями должны размещаться на территории Российской Федерации. Требования к порядку создания, развития, ввода в эксплуатацию, эксплуатации, вывода из эксплуатации государственных информационных систем утверждает Правительство Российской Федерации.

Защиту персональных данных регулирует новая ст. 15.5, ограничивающая доступ к информации, которая обработана с нарушением законодательства о персональных данных. Согласно этой статье должна быть создана информационная система «Реестр нарушителей прав субъектов персональных данных» и прописан порядок его ведения. В ч. 4 ст. 16 «Защита информации» введен пункт 7, обязывающий базы данных с персональными Аанными граждан Российской Федераџии хранить на территории Российской Федераџии.

В 2015 г. введены ст. 10.3 об обязанностях оператора поисковой системы, ст. 12.1, регламентирующая государственное регулирование в сфере использования российских программ для эмектронных вычислительных машин и баз 
Аанных. В последней прописано создание единого реестра российского программного обеспечения, необходимое Аля расширения использования российских программ и баз данных и для оказания их владемьцам (правообладатемям) господАержки. Прописаны требования, которым должно удовлетворять программное обеспечение для включения в реестр. Реестр находится по аАреcy https:/ / reestr.minsvyaz.ru/, и с конца января 2016 г. в него включено более 2800 программ и баз данных.

В 2017 г., Аанный Закон дополнен новыми статьями. Так, в ст. 10.4 дано опредемение новостного агрегатора (обработка и распространение новостной информации, доступ более мимлиона пользователей Интернета в течение суток) и требования, которые они домжны соблюдать. Нельзя допускать использование новостного агрегатора в цемях разглашения государственной или иной охраняемой законом тайны, распространения публичных призывов к осуществлению террористической деятельности, экстремистских материалов, а также материалов, пропагандирующих порнографию, насимие и жестокость.

Статья 10.5 теперь содержит определение владельца аудиовизуального сервиса (распространения в Интернете совокупности аудиовизуальных произведений, находящихся на территории Российской Федераџии, доступ более мимлиона пользователей Интернета в течение суток) и требования, которые необходимо соблюдать. Нельзя допускать использование аудиовизуального сервиса для разглашения государственной или иной тайны, охраняемой законом, Аля призывов к террористической деятельности, распространения экстремистских материалов, материалов, пропагандирующих порнографию, насилие и жестокость, осуществлять кмассификацию аудиовизуальных произведений, чтобы не причинить вреА детям.

С октября 2017 г. начала действовать ст. 15.6-1 о порядке ограничения доступа к копиям заблокированных сайтов, а с 1 ноября - ст. 15.8, регламентирующая меры для противодействия использования информационных ресурсов и сетей, через которые осуществляется доступ к ресурсам и сетям, ограничен на территории РФ.

Таким образом, изменения в Законе № 149-ФЗ направлены на усимение информаџионной безопасности, а следовательно, развитие и совершенствование всей системы национальной безопасности страны по таким направлениям, как защита каналов связи, сетевая и эксплуатаџионная безопасность, компьютерная безопасность, аАминистративная безопасность. Нормативно-правовое усиление по этим направлениям способно комплексно решать кмючевые задачи по сохранению и защите информаџионных ресурсов России, укреплению ее межАународного авторитета, повышению эффективности работы по снижению криминальной напряженности, защите прав, свобод и безопасности российских граждан в системе их информаџионно-коммуникаџионных взаимодействий. В результате компонент информаџионной безопасности в системе наџиональной безопасности приобретает особый вес и актуальность по сравнению с Аругими ее эмементами. 
ГАавная тенденция, на которую следует обратить внимание в проведенном анализе, - это обозначение законодателем особой роли государства в системе защиты культурно-исторических и демократических ценностей обшества. Аанное обстоятельство во многом предопределяет и специфические требования, которые будет предъявцять общество к уровню компетентности и гражданской ответственности государственных служащих, руководящих реализацией политики и принимающих решения в сфере информационной безопасности России.

\section{Библиографический список}

1. О Стратегии национальной безопасности Российской Федерации: Указ Президента РФ от 31 дек. 2015 г. № 683 // С3 РФ. 2016. № 1 (ч. II). Ст. 212.

2. Брянцева O.В., Филиппова Е.А. Развитие электронного правительства в России и его представление в средствах массовой информации // Право, наука, образование: традиции и перспективы: сборник статей по материалам международной научно-практической конференции, посвященной 85-летию Саратовской государственной юридической академии (в рамках VII Саратовских правовых чтений, Саратов, 29-30 сентября 2016 г.) / отв. ред. Е.В. Вавилин [и др.]. Саратов, 2016. С. 174-175.

3. Архангельская E.B. Представление и обработка данных о преступлениях с помощью компьютерной техники // Вестник Саратовской государственной юридической академии. 2016. № 1 (108). C. 235-241.

4. О Стратегии развития информационного общества в Российской Федерации на 2017-2030 годы: Указ Президента РФ от 9 мая 2017 г. № 203 // СЗ РФ. 2017. № 20. Ст. 2901.

5. Информационная безопасность систем организационного управления: Теоретические основы / под ред. Н. Кузнецова, В. Кульбы. М., 2006.

6. Асланов Р.М. Зарубежный опыт правового регулирования обеспечения информационной безопасности // Политика и общество. 2012. № 2 (86).

7. Терещенко Л.К. Модернизация информационных отношений и информационного законодательства. М., 2013.

8. Полякова Т.А., Акулова Е.В. Развитие законодательства в области обеспечения информационной безопасности: тенденции и основные проблемы // Право. Журнал Высшей школы экономики. 2015. № 3. С. 4-17.

9. Об информации, информатизации и защите информации: Федер. закон от 20 февр. 1995 г. № 24-Ф3 // СЗ РФ. 1995. № 8. Ст. 609.

10. Доктрина информационной безопасности Российской Федерации (утв. Президентом РФ 9 сент. 2000 г. № Пр-1895) // Российская газета. 2000. № 187, 28 сент.

11. Об информации, информационных технологиях и о защите информации: Федер. закон от 27 июля 2006 г. № 149-ФЗ (в ред. от 19 дек. 2016 г. с изм. и доп. от 1 янв. 2017 г.) // СЗ РФ. 2006 г. № 31 (ч. 1). Ст. 3448 .

12. Брянцева О.В., Филиппова Е.А. Обзор нормативно-правовых актов, регулирующих электронное правительство // Современные тенденции развития науки и технологий: сборник по материалам XXIII международной научно-практической конференции, г. Белгород, 28 февраля 2017 г. Белгород, 2017. № 2-6. С. 22-28.

13. Об утверждении Доктрины информационной безопасности Российской Федерации: Указ Президента РФ от 5 дек. 2016 г. № 646 // СЗ РФ. 2016. № 50. Ст. 7074. 